\title{
Qualidade e preço da manga Tommy Atkins comercializada em São Luís-MA
}

\section{Quality and price of Tommy Atkins mango sold in São Luís-MA}

Antonio Jeronimo de Almeida Neto ${ }^{1 *}$, Clodoaldo Rodrigues Pereira ${ }^{2}$, Jonas de Jesus Gomes da Costa Neto ${ }^{1}$, Janaina da Silva Gomes ${ }^{1}$, Deusur Gonçalves Sampaio ${ }^{1}$, Leidiana de Sousa Lima ${ }^{1}$

\section{RESUMO}

As características de produção devem estar intimamente ligadas aos fatores pós-colheita, para que os produtos com elevada produtividade, excelente grau de qualidade e benéficos à saúde possam estar disponíveis à mesa do consumidor. Esta pesquisa foi realizada com o objetivo de estudar as variações do preço da manga comercializada em São Luís-MA, assim como identificar a qualidade das mesmas. Foi feita a divisão geográfica do município de acordo com os pontos cardeais e selecionados em cada região um supermercado de grande porte dentro de uma mesma rede. Foi utilizado o delineamento experimental de blocos ao acaso, com quatro tratamentos e os dias de coleta sendo as repetições. As variáveis estudadas foram: Peso do Fruto, Comprimento Longitudinal, Diâmetro do Fruto, Sólidos Solúveis, pH, Acidez Titulável , Rátio e o preço por quilo praticado em cada estabelecimento comercial. Os frutos comercializados obedecem a um padrão mínimo de qualidade para a sua comercialização.

Palavras-chave: Mangifera indica L; Análises; Consumidor

\section{ABSTRACT}

The characteristics of production shall be closely related to post-harvest factors, so that products with high productivity, excellent degree of quality and beneficial to health may be available to the consumer's table. This research was conducted with the objective of studying the variations in the price of mangoes sold in São Luís-MA, also was identify their quality. It was done the geographical division of the city according to the cardinal points and a large supermarket within the same network was selected in each region. It was used the experimental design of randomized blocks with four treatments and the days of collecting the repetitions. The variables studied were: Fruit weight, Longitudinal Length, diameter of the fruit, soluble solids, $\mathrm{pH}$, Titratable Acidity, Ratio and the price per pound in each retail store. The fruits marketed had a minimum standard of quality for your marketing.

Keywords: Mangifera Indica L; Analyses; Consumer

\footnotetext{
${ }^{1}$ Instituto Federal do Maranhão, IFMA, Campus São Luis - Maracanã

*E-mail: jeronimo@ifma.edu.br
} 


\section{INTRODUÇÃO}

A manga in natura tem uma alta aceitação Entre os consumidores. Em 2012, as frutas frescas exportadas renderam para o Brasil cerca de us\$ 619 milhões, foram exportadas 693 mil toneladas de frutas, e destes, a manga trouxe mais divisas para o país, com us\$ 137 milhões, enquanto a Bahia, grande produtor de manga, foi quem mais arrecadou no comércio internacional chegando a us\$130,3 milhões (IBRAF, 2013).

Devido a esse panorama na produção dessa fruta Chitarra e Chitarra (2005) ressaltam que as características de produção devem estar intimamente ligadas aos fatores pós-colheita, para que os produtos com elevada produtividade, excelente grau de qualidade e benéficos à saúde possam estar disponíveis à mesa do consumidor.

Por isso, levando-se em consideração a cidade de São Luís, onde existem vários bairros que abrigam diferentes classes sociais e econômicas, é possível haver se existe relação entre o preço e a localização estabelecimento onde frutos de manga comercializados.

Para entender essa questão podemos relacionar ao fato de que esse fenômeno de preços elevados acontece pela ação dos comerciantes que buscam obter maiores lucros junto a consumidores de maior poder aquisitivo, também se relaciona a maior exigência por parte do consumidor por frutos melhores, que provoca aumento de preço e também pelo fato de que a perda de qualidade das frutas durante seu manuseio pode acarretar redução do volume ofertado provocando elevação dos preços e diferenças na destinação do produto.

Conforme Carvalho (1998) estudando o processo de tomada de decisão de compras no setor de frutas verificou que os atributos de qualidade das frutas foram considerados na avaliação de alternativas da fase de pré-compra do processo e que para (CHITARRA; CHITARRA, 2005) as características externas de qualidade, percebidas pelo tato e visão, são importantes na diferenciação do produto, particularmente, na decisão de compra. No momento que o consumidor se depara com a fruta no ato da compra realiza-se uma análise rígida visando eliminar o risco, que está diretamente relacionado com a quantia de dinheiro envolvido, por isso mecanismos são desenvolvidos, como por exemplo, comprar produtos de empresas já conhecidas; na mesma mão as empresas devem conhecer esses fatores e desenvolver mecanismos para aumentar o número de informações ao consumidor e com isso elevar a venda dos seus produtos (KOTLER, 1998). 
De acordo com Araújo, Moraes e Carvalho (2017) os fatores determinantes na mudança do padrão de produção e consumo da manga no mercado nacional, observaram que no que se refere ao tamanho do fruto, as avaliações dos pesquisadores indicaram que a Palmer, Tommy Atkins e Haden são as que possuem melhor avaliação, seguidas por Keitt e Kent e por último, variedades como Espada e Rosa. Segundo estes pesquisadores, as notas da Keitt e Kent são equivalentes às da Espada, porém diferem as razões para isso. Enquanto o tamanho avantajado da Keitt e Kent prejudicam sua aceitação, o tamanho reduzido da espada também causa esse efeito. Portanto fica claro que quanto ao tamanho a variedade estudada tem grande preferencia pelo consumidor.

Ume estudo realizado por (ALMEIDA NETO et al., 2010) avaliou que são necessárias ações junto aos comerciantes para que mudem a sua forma de exposição dos frutos para que seja possível e prolongar o tempo de prateleira e assim obter melhores preços.

Para Leite et al., 2010, desde a colheita até a comercialização devemos acompanhar a qualidade do fruto, fato este que deve ser mais criterioso no que diz respeito a forma que os mesmo são manuseados, principalmente, quando se trata do consumo do fruto in natura, fazendo-se necessários a adoção de padrões visando uma correta classificação do produto.

Verifica-se que são necessários mais estudos relacionados com a comercialização das frutas, em especial a manga Tommy Atkis uma vez que o comércio dessa fruta é fortemente afetado por se tratar de um fruto proveniente de outras regiões do Nordeste. A identificação de estratégias comerciais existentes para comercialização desta fruta proporciona gerar informações que venham contribuir com os agentes envolvidos nesta cadeia produtiva.

A preocupação com a saúde também deve ser levada em consideração principalmente quando se trata da compra de alimentos, assim como a necessidade de economizar no ato da compra. Para isso o ideal que é sejam observadas algumas características da fruta que remetam a sua qualidade, porem alguns fatores não podem ser vistos a olho nu e assim podem passar despercebidos aos clientes, sendo necessárias pesquisas que associem a qualidade do fruto ao preço praticado.

Dentro deste contexto, esta pesquisa foi realizada com o objetivo de estudar as variações do preço da manga comercializada em São Luís-MA, assim como identificar a qualidade das mesmas. 


\section{MATERIAL E MÉTODOS}

Foi feita a divisão geográfica do município de São Luís, tendo como base o centro de distribuição de frutos, logo em seguida selecionado em cada região um supermercado (Cohama, Anjo da Guarda, São Cristóvão, João Paulo) de grande porte dentro de uma mesma rede; em cada estabelecimento foram identificadas as variedades de manga disponíveis para a venda conforme informações expostas disponíveis para o consumidor. As frutas neste projeto foram adquiridas apenas quando estas estiverem expostas a venda com placa indicadora da variedade e preço, não houve questionamentos junto a vendedores ou qualquer funcionário do estabelecimento e não foram comprados frutos quando não existiam placas nos estabelecimentos.

A variedade estudada foi a manga Tommy Atkins. Para esta variedade foram identificadas as cores e adquiridos frutos apenas frutos da Cor 04 para análise semanal. As frutas foram adquiridas nos bairros do João Paulo, Bacanga, São Cristóvão e Cohama, os quais foram semanalmente visitados.

Figura 1 - Aspecto externo e interno da manga em função do grau de maturação.

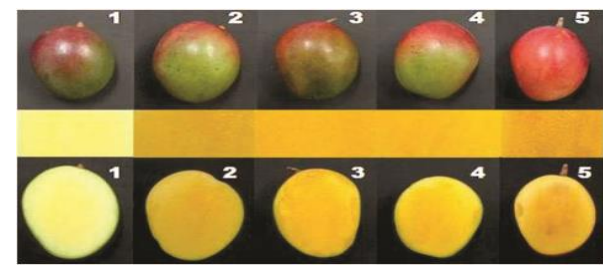

Fonte: frutas Brasil (2019)

As coletas das frutas ocorreram, nas quintas-feiras e logo em seguida aplicados os tratamentos (Peso do Fruto, Comprimento Longitudinal, comprimento transversal, Sólidos Solúveis, pH, Acidez Titulável, Rátio e o preço). As repetições foram os dias de coleta, onde foram realizadas quatro visitas aos estabelecimentos comerciais em cada período. foi utilizado o delineamento experimental de blocos ao acaso, com quatro tratamentos (as áreas geográficas do município) e os dias de coleta sendo as repetições. As variáveis estudadas foram: Peso do Fruto, Comprimento Longitudinal, Diâmetro do Fruto, Sólidos Solúveis, pH, Acidez Titulável, Rátio e o preço por quilo praticado em cada estabelecimento comercial. O peso do fruto $(\mathrm{g})$ foi determinado com o auxílio de balança digital. O diâmetro do fruto $(\mathrm{cm})$ foi medido com uma fita métrica, na parte 
exterior e mediana do fruto, o comprimento longitudinal aferiu-se com fita métrica de onde começa a polpa até a ponta do fruto, e os resultados devidamente expressos em centímetros.

Os sólidos solúveis- SS (\%) foram determinados por leitura direta em refratômetro digital, e o $\mathrm{pH}$ foi determinado diretamente por meio de um potenciômetro. A acidez foi determinada através da titulação.

\section{Aferições}

\subsection{Preço dos frutos}

Foi observado e anotado os preços encontrados e praticado pelo estabelecimento de venda do fruto no ato da aquisição

\section{$\underline{\text { 2.2 Pesos do Fruto Total }}$}

Do buque ou penca foram retirando os dedo (fruto) da almofada e seu peso obtido em gramas $(\mathrm{g})$ na balança analítica.

\subsection{Comprimento Longitudinal}

O comprimento longitudinal foi determinado a medida a parte no início da base do pedúnculo seguindo a curvatura externa até o ápice com uso de fita métrica.

\section{$\underline{\text { 2.4 Comprimento Transversal }}$}

O comprimento Transversal foi medido na parte mediana fruto com auxílio de um paquímetro digital com resultados da média em $\mathrm{mm}$.

\subsection{Sólidos solúveis}

O teor de sólidos solúveis foi determinado em leitura direta no refratômetro portátil com escala de 0 - $32{ }^{\circ}$ Brix, com os resultados foram feitos as correções da temperatura. Duas gotas do suco da amostra foram utilizada da acidez, procedimento segue normas do instituto adolfo lutz, (2008).

\section{$2.6 \mathrm{pH}$}

Determinação do $\mathrm{pH}$ foi realizado com pHmetro digital, utilizado $10 \mathrm{~g}$ da amostra diluída e homogeneizada em $15 \mathrm{ml}$ de água destilada, foi usado o pHmetro direto no suco na amostra para leitura do $\mathrm{pH}$, seguindo as normas do instituto adolfo lutz,(2008)

\subsection{Acidez titulável}

Acidez titulável foi utilizada $10 \mathrm{~g}$ de cada da todas em triplicata e homogeneizada manualmente utilizou $75 \mathrm{ml}$ de água destilada, utilizou-se o indicador fenolftaleína 1\% e titulação com hidróxido de sódio $0,1 \mathrm{~N}$. A titulação em agitação constante até 
coloração rósea, deixado persistente por 30 segundos, seguindo normas do instituto adolfo lutz,(2008). Os cálculos foram efetuados conforme a equação a seguir.

$$
\begin{aligned}
& \mathrm{At}=\frac{V \times f \times M \times 100}{\mathrm{P}} \\
& \mathrm{V}=\mathrm{n}^{\circ} \text { de } \mathrm{mL} \text { da solução de hidróxido de sódio gasto na titulação; } \\
& \mathrm{f}=\text { fator de correção da solução de hidróxido de sódio }(\mathrm{f})=01 ; \\
& \mathrm{P}=\text { massa da amostra em g ou volume pipetado em ml; } \\
& \mathrm{M}=\text { molaridade da solução de hidróxido de sódio; }
\end{aligned}
$$

\subsection{Rátio}

O valor do Rátio foi determinado através da relação entre sólidos solúveis totais e acides total utilizando o seguinte calculo.

\subsection{SST/AT}

Os resultados foram submetidos à análise de variância e as médias separadas pelo teste Tukey, a 5\% de probabilidade. As análises foram realizadas pelo programa STATISTIC 7.0.

\section{RESULTADOS E DISCUSSÃO}

Aplicando o ANOVA para as variáveis PESO, brix, $\mathrm{pH}$, acidez, ratio, comprimento transversal e longitudinal em função do tratamento (localidades) não houve diferenças significativas $(\mathrm{p}>0,05)$ para $95 \%$ de confiança. Isso se deve ao fato que os frutos comercializados para a cidade de São Luís devem obedecer a um padrão mínimo de qualidade exigido no ato da compra, comprovando também que estes frutos não são de "ultima safra" que não têm classificação exigida.

Sobre as variáveis Brix, $\mathrm{pH}$, Acidez, ratio, peso, comprimento transversal e longitudinal a semelhança estatística está relacionada ao classificação mínima exigida no ato da compra, que se refere ao tamanho e peso dos frutos, onde as frutas neste estágio de desenvolvimento também expressam aceitáveis níveis de qualidade para o consumidor.

Aplicando o ANOVA para a variável preço em função do tratamento (localidades) observa-se na Tabela 1 , que houve diferenças significativas $(\mathrm{p}<0,05)$ para $95 \%$ de confiança. Observa-se que nos supermercados dos Bairros São Cristóvão, Cohama e João Paulo foram iguais estatisticamente $(\mathrm{p}>0,05)$ contudo diferentes do bairro Anjo da Guarda $\mathrm{p}<(0,05)$. Assim nota-se que os preços praticados na Cohama (R\$ 3,27), São 
Cristovão ( $\mathrm{R} \$ 3,33)$ e João Paulo $(\mathrm{R} \$ 3,61)$ foram menores que os praticados no bairro Anjo da Guarda (R\$ 3,80). Este preço elevado no bairro Anjo da Guarda pode está relacionado à distância entre o Centro de distribuição de frutas e a localidade em questão, onde o frete passa a ter um maior custo provocando aumento de preço entre as frutas repassado para o consumidor final. Contudo outro fator que pode influenciar o elevado preço do fruto no anjo da guarda, é a ausência de estabelecimentos comerciais nas proximidades comercializando o mesmo fruto. Assim como este resultado do preço elevado naquela localidade também pode estar relacionado a ausência de outro supermercado de grande porte nas proximidades .

Tabela 1 - Valores médios para o preço de frutos de manga conforme os locais de compra no município de São Luís-MA, 2019:

\begin{tabular}{|c|c|c|c|}
\hline \multicolumn{4}{|c|}{ Locais de compra } \\
\hline \multicolumn{4}{|c|}{ PREÇO (R\$) } \\
\hline Anjo da Guarda & $\begin{array}{l}\text { João } \\
\text { Paulo }\end{array}$ & $\begin{array}{c}\text { São } \\
\text { Cristóvão }\end{array}$ & Cohama \\
\hline $3,798 \mathrm{a}$ & $3,615 \mathrm{ab}$ & $3,336 \mathrm{~b}$ & $3,272 \mathrm{~b}$ \\
\hline \multicolumn{4}{|c|}{ CV 0,03157 } \\
\hline
\end{tabular}

${ }^{1}$ Médias seguidas da mesma letra nas colunas não diferem entre si ( $\left.p>0,05\right)$ pelo teste de Tukey. Fonte: Almeida Neto (2019)

Aplicando o ANOVA para a variável peso em função do período (meses) observase na Tabela 2 que não houve diferenças significativas ( $p>0,05$ ) para $95 \%$ de confiança. Contudo foi encontrada diferença estatística significativa para a variável preço em função do período (meses) observa-se na Tabela 2 que houveram diferenças significativas $(\mathrm{p}<0,05)$ para $95 \%$ de confiança. Observa-se que os preços dos meses de agosto $(R \$ 4,09)$ e setembro $(R \$ 3,84)$ foram iguais estatisticamente ( $p>0,05)$ contudo diferentes do mês de outubro $(\mathrm{R} \$ 3,33)$ e novembro $(\mathrm{R} \$ 2,75) \mathrm{p}<(0,05)$ que também foram diferentes entre si. Assim nota-se que os preços praticados em novembro foram menores $(\mathrm{R} \$ 2,75)$ e os preços praticados em setembro e agosto foram maiores. Este resultado confronta com a pesquisa Lima et al. (2013) os quais, estudando comportamento dos preços da manga exportada do Brasil no período compreendido entre 2004-2012, observaram que devido à sazonalidade, o preço da manga tende a estar acima da média nos $1^{\circ}, 2^{\circ}$ e $4^{\circ}$ trimestres e abaixo da média no $3^{\circ}$ trimestre, que é justamente o período de grande oferta de manga na região do Submédio do Vale do São Francisco, devido à floração natural das mangueiras da região, causando forte redução dos preços da fruta. Porém os valores de preço para os meses compreendidos entre 
agosto e novembro, encontrados em São Luís, mostram que no mês de agosto, ainda existe pouca oferta do produto no mercado devido ao final do período de entressafra, a oferta vai aumentando nos meses de setembro e outubro até o mês de novembro, onde no final de outubro para novembro o pico da colheita de manga e com isso maior oferta de produto e como obediência a lei de mercado os preços caem.

Aplicando o ANOVA com teste de média (Tukey 0,05) para a variável brix em função do período (meses) observa-se na tabela que houveram diferenças significativas $(\mathrm{p}<0,05)$ para $95 \%$ de confiança. Observa-se que os BRIX dos meses de agosto $(12,87)$ foi igual ao brix dos meses de setembro $(12,15)$, outubro $(12,17)$ e novembro $(13,5)$ foram iguais estatisticamente ( $p>0,05)$, contudo o mês de novembro $(13,5)$ foi diferente de setembro $(12,15)$ e outubro $(12,17)$. Assim nota-se que o brix observado em novembro foi maior quando comparado a setembro e outubro. Os valores de sólidos solúveis encontrado no presente trabalho assemelham-se aos encontrados por XAVIER et al 2009 que encontraram teor de solido solúveis entre os meses de agosto a outubro com valores que variavam entre $13 \%$ e 14,95\%. Para Hojo et al. (2009), os quais estudaram a qualidade da manga com o uso de cloreto de cálcio, observaram um declínio na acidez da manga quando submetido ao tratamento com o cálcio tendo uma variação de 10,61 a 9,50 no seu teor de sólidos solúveis. Com o fím da safra que ocorre exatamente em meados do mês de novembro é normal essa alta taxa de sólidos solúveis, Gonçalves (2009) explicam que há degradação dos ácidos orgânicos, reduzindo a adstringência e o sabor acido do fruto. Assim, aumentam a relação teor de sólidos totais, representado principalmente pelos açucares, e a acidez da fruta, promovendo o sabor doce característico. $\mathrm{O}$ maior brix está relacionado ao menor $\mathrm{pH}$. $\mathrm{O}$ maior brix em novembro está relacionado ao maior estresse hídrico e resultado de uma eficiente indução floral resultando em frutos de melhor qualidade em relação as qualidades organolépticas, favorecendo frutos com bons níveis de brix e acidez.este elevado brix no mês de novembro esta relacionado com o fim da safra na regiao do vale do São Francisco que ocorre nesse mês onde a maioria dos frutos encontrao-se maduros o que ocasiona o elevado brix nesses frutos.

Aplicando o ANOVA com teste de média (Tukey 0,05) para a variável pH em função do período (meses) observa-se na tabela que houveram diferenças significativas $(\mathrm{p}<0,05)$ para $95 \%$ de confiança. Observa-se que o $\mathrm{pH}$ dos meses de agosto $(2,80)$ foi igual ao $\mathrm{pH}$ dos meses de setembro $(2,86)$, outubro $(2,42)$ foram iguais estatisticamente 
( $>>0,05)$ contudo o mês de novembro $(1,87)$ foi diferente de setembro $(2,86)$ e outubro $(2,42)$ e agosto $(2,80)$. Assim nota-se que o $\mathrm{pH}$ observado em novembro foi menor quando comparado a setembro e outubro. Os valores de $\mathrm{pH}$ encontrado diferem-se do valores encontrados por Modesto (2013) que em sua pesquisa encontrou valores e pH para a variedade estudada que variavam de 3,62 a 4,4. Porém o valor encontrado no mês de novembro esta ligado ao grau de maturação dos frutos nessa época do ano pois quanto menor o pH maior o grau de maturação do fruto isso pode ser melhor observado quando observamos o grau brix para o mesmo período que é o mais alto em torno de 13,50 .

Aplicando o ANOVA com teste de média (Tukey 0,05) para a variável acidez em função do período (meses) observa-se na tabela que houveram diferenças significativas $(\mathrm{p}<0,05)$ para $95 \%$ de confiança. Observa-se que a acidez dos meses de agosto $(0,20)$ foi igual a acidez do mês de setembro $(0,39)$ sendo diferente dos meses de outubro $(0,55)$ e novembro $(0,74)$. Os meses de outubro e setembro foram iguais estatisticamente $(p>0,05)$, contudo o mês de novembro foi diferente de setembro $(0,39)$ e agosto $(0,20)$ e igual a outubro $(0,74)$. Assim nota-se que a acidez foi maior nos meses de outubro e novembro. Para Andrade (2009), esta redução da acidez ocorre devido a degradação dos ácidos orgânicos, reduzindo a adstringência e o sabor acido do fruto. A relação teor de sólidos totais, representado principalmente pelos açucares e acidez da fruta aumenta, promovendo o sabor doce característico.

Aplicando o ANOVA com teste de média (Tukey 0,05) para a variável ratio em função do período (meses) observa-se na tabela que houveram diferenças significativas $(\mathrm{p}<0,05)$ para $95 \%$ de confiança.

Observa-se que o Rátio dos meses de setembro $(38,32 \mathrm{~cm})$, outubro $(24,35 \mathrm{~cm})$ e novembro $(19,46 \mathrm{~cm})$ foram iguais estatisticamente $(\mathrm{p}>0,05)$, sendo outubro e novembro diferentes de agosto $(67,74) \mathrm{p}<0,05$. Assim nota-se que o Rátio foi maior no mês de agosto. O Índice de maturação é obtido através da razão entre o teor de sólidos solúveis e a acidez titulável do suco extraído da polpa dos frutos (SS/AT) este parâmetro é muito importante no que se refere ao ponto de maturação dos frutos esse parâmetro é o que melhor representa a doçura do fruto. Modesto, 2013, estudando mangueiras subtropicais encontrou valores de Rátio que variavam de 76,81 a 45,42 valores esses que se assemelham aos valores diferentes encontrados na presente pesquisa. Segundo Simão e Gomes (1996) o aumento da quantidade de açúcares e a 
redução da acidez, estão relacionados ao processo de amadurecimento e varia de acordo som o local do fruto. Carvalho et al. (2004) estudando a qualidade de diversas variedades de manga encontrou teores de acidez para a variedade estudada de 0,20\% de acido cítrico, porem este parâmetro varia muito de acordo com o grau de maturação do fruto. Hojo et al.(2009) estudando a qualidade da manga com o uso de cloreto de cálcio encontraram concentrações de acido cítrico na porcentagem de $0,79 \%$ nesse estudo observou-se que a acidez aumentava conforme a concentração de cálcio.

Não houve diferença estatística significativa para o "comprimento transversal" e "longitudinal" em função do período (meses) ( $p$ > 0,05) para $95 \%$ de confiança. Os comprimentos transversal e longitudinal estão relacionados com o peso que mostra que também durante os meses de colheita os frutos também seguiram padrões mínimos destas variáveis quanto a colheita e classificação.

Tabela 2 - Valores médios preço (R\$), ${ }^{\circ} \mathrm{BRIX}, \mathrm{pH}$, acidez e ratio dos frutos de manga conforme o período de compra no município de São Luís-MA, São Luís-MA, 2019:

\begin{tabular}{lccccc}
\hline & PREÇO $(\mathrm{R} \$)$ & ${ }^{\mathrm{O}} \mathrm{BRIX}$ & $\mathrm{pH}$ & ACIDEZ & RATIO \\
\hline Agosto & $4,090 \mathrm{a}$ & $12,87 \mathrm{ab}$ & $2,800 \mathrm{a}$ & $0,205 \mathrm{c}$ & $67,74 \mathrm{a}$ \\
Setembro & $3,840 \mathrm{a}$ & $12,15 \mathrm{~b}$ & $2,861 \mathrm{a}$ & $0,392 \mathrm{bc}$ & $38,32 \mathrm{ab}$ \\
Outubro & $3,335 \mathrm{~b}$ & $12,17 \mathrm{~b}$ & $2,426 \mathrm{ab}$ & $0,551 \mathrm{ab}$ & $24,35 \mathrm{~b}$ \\
Novembro & $2,756 \mathrm{c}$ & $13,50 \mathrm{a}$ & $1,876 \mathrm{~b}$ & $0,748 \mathrm{a}$ & $19,46 \mathrm{~b}$ \\
\hline CV $(\%)$ & 0,03157 & 0,21579 & 0,07152 & 0,00949 & 185,87 \\
\hline
\end{tabular}

${ }^{1}$ Médias seguidas da mesma letra nas colunas não diferem entre si $(p>0,05)$ pelo teste de Tukey. Fonte: Almeida Neto (2019)

Observa-se que não há correlação forte entre preço e brix uma vez que o $\mathrm{R}=0,30$ e p valor $(0,25)>0,05$. Portanto o preço não tem relação com o brix, mas influências da localidade e período como vistos nas análises de ANOVA supracitadas. Esses dados mostram que nem sempre é possível relacionar a qualidade ao preço do produto conforme Figura 1. 
Figura 2 - Comparação do preço em função do brix:



Fonte: Almeida Neto (2019)

\section{CONCLUSÕES}

Os frutos comercializados em São Luís obedecem a um padrão mínimo de qualidade para a sua comercialização.

O melhor local para comprar manga quanto ao preço são nos bairros Cohama, João Paulo e São Cristóvão.

O mês de novembro apresentou-se como o período ideal para a compra da manga tendo em vista que neste período os frutos se encontravam mais doces e mais baratos.

Os frutos colhidos mais tardiamente apresentaram maiores Brix.

$\mathrm{O} \mathrm{pH}$ e a acidez apresentados pelas frutas foram menores no final da safra.

A menor acidez da Tommy Atkins resultou em um maior "ratio".

\section{REFERÊNCIAS}

ALMEIDA NETO et al. fatores que influenciam na escolha do dia e estabelecimento para compra de frutas. In: Congresso Norte Nordeste de Pesquisa e Inovação, 11.,2010, Maceió. Anais [...]. Maceió: IFAL, 2010. Disponível em: < http://connepi.ifal.edu.br/ocs/anais/> Acesso em: 22 jan.2019

ANDRADE, E. C. B de: Análise de alimentos: uma visão química da nutrição. Livraria Varela, 2006. 
ARAUJO, D.O; MORAES ,J.A.A; CARVALHO,J.L.M.de. fatores determinantes na mudança do padrão de produção e consumo da manga no mercado nacional; Revista em Agronegócio e Meio Ambiente, Maringá- PR, v.10, n. Ed.esp. p51-73.

CARVALHO, C.R.L; ROSSETTO,C.J; MANTOVANI,D.M.B; MORGANO,M.A; Avaliação de cultivares de mangueira selecionadas pelo Instituto Agronômico de Campinas comparadas a outras de importância comercial ; Revista Brasileira de Fruticultura, Jaboticabal, v.26, n.2, p.264-271, 2004.

CASTRO, J. V de; BORTOLETTO, N. Avaliação de cultivares de mangueira selecionadas pelo instituto agronômico de campinas comparadas a outras de importância comercia.

Revista Brasileira de Fruticultura, Jaboticabal - sp, v. 26, n. 2, p. 264-271, agosto 2004.Disponivel em : http://www.scielo.br/pdf/\%0d/rbf/v26n2/21822.pdf. Acesso em 26 jan. 2019

CARVALHO, Gabriela Fazio de. Consumo de Frutas: um estudo exploratório. 1998. Tese de Doutorado. Universidade de São Paulo.

CHITARRA, M. I. F.; CHITARRA, A. B. Pós-colheita de frutas e hortaliças: fisiologia e manuseio. 2. ed. Revisada e ampliada. Lavras: UFLA, 2005.

HOJO,R.H ; SÃO JOSÉ,A.R; HOJO,E.T.D; ALVES,J.F.T; REBOUÇAS,T.N.H; DIAS,N.O; qualidade de manga 'tommy atkins' pós-colheita com uso de cloreto de cálcio na pré-colheita1; Revista Brasileira de Fruticultura, Jaboticabal, v. 31, n. 1, p. 062-070, março 2009 disponível em:

https://www.researchgate.net/profile/tiyoko_reboucas/publication/262741008_quality_o f_tommy_atkins'_mangoes_in_post-

harvest_with_calcium_choride_spray_use_in_the_pre-

harvest_period/links/569ceed208ae2f0bdb8d1119.pdf acesso em 26 jan. 2019

IBRAF. Balanço das exportações de frutas em 2012. 2013. Disponível em: http://negociosdaterra.com.br/2013/02/08/balanco-das-exportacoes-de-frutas-em-2012

INSTITUTO ADOLFO LUTZ. Normas analíticas, métodos químicos e físicos de alimentos. 3 ed. São Paulo: IAL, 1985. v. 1, 553p.

INSTITUTO ADOLFO LUTZ. Normas Analíticas do Instituto Adolfo Lutz. v. 1:

KOTLER, P. Administração de marketing: análise, planejamento, implementação e controle. Tradução Aílton Bomfim Brandão. 5. Ed. São Paulo: Atlas, 1998.

LEITE, G. A; MEDEIROS, E. V. de; MENDONÇA, V.; MORAES, P. L. D. de; qualidade pós colheita da banana 'pacovan 'comercializada em diferentes estabelecimentos no município de Mossoró-RN. Revista Brasileira de Ciências Agrárias, Recife, v.5, n.3, jul.-set., 2010. Disponível em : http://www.agraria.pro.br/ojs 2.4.6/index.php?journal=agraria\&page $=$ article $\&$ op $=$ view $\&$ path $\% 5 \mathrm{~B} \% 5 \mathrm{D}=$ agraria_v5i3 a614\&path\%5B $\% 5 \mathrm{D}=3563$ 
LIMA, J.R.F.de .et al . Comportamento dos preços da manga exportada do brasil: 20042012, Organizações Rurais \& Agroindustriais, Lavras, v. 15, n. 3, p. 370-380, 2013. Disponível em: https://ainfo.cnptia.embrapa.br/digital/bitstream/item/96354/1/JoaoRicadro-2013 pdf . Acesso em: 25 jan.2019

MODESTO, J.H; Produtividade, sazonalidade e análises tecnológicas de frutos de cultivares de mangueira em condições subtropicais. 2013.65 f. dissertação (mestrado em agronomia ) Universiade Estadual Paulista Júlio de Mesquita Filho, Faculdade de Ciências Agronômicas Campus de Botucatu,Botucatu, 2013.

SIMÃO,S; GOMES,F.P; açucares e acidez: sua distribuição em torno da manga (mangifera indica ,L) Revista de Agricultura, v.71. n.1, p.4-12. Jun.1996.

XAVIER, I.F; LEITE, G .A; MEDEIROS, E.V.DE; MORAIS,P.L.D; LIMA ,L.M. Qualidade pós-colheita da manga 'Tommy Atkins' comercializada em diferentes estabelecimentos comerciais no município de Mossoró-RN. Revista Caatinga, Mossoró, v.22, n.4, p.7-13, out. 2009. Disponível em:

https://periodicos.ufersa.edu.br/index.php/caatinga/article/view/568 acesso em: 26 jan .2019 . 